\title{
Recruiting, training, and working with PGR student reviewers on an academic journal
}

\begin{abstract}
While postgraduate researchers are encouraged to submit work for consideration in Compass, behind the scenes of the journal, each issue was previously based solely upon the reviews and voices of staff in Higher Education. In this way, the makeup of the journal was typical of most other academic journals. By way of trying to increase levels of interaction with the journal among postgraduate researchers (PGRs), an email call was sent out to invite PGRs to consider the opportunity of joining Compass as a student reviewer. It was envisioned that the collaboration of staff and student reviewers would lead to the publication of a more inclusive journal. An application process was implemented as part of the recruitment stage. PGRs had to select a published text from the Compass archives and review the piece using a standard review form. Each application was peer reviewed and individuals were then informed of the decision. Three PGRs and an Intern participated in a training session which involved introducing them to the scope and aims of the journal more explicitly. It has been found that being a student reviewer for Compass has helped the PGRs to develop their professional identity. The role which PGR student reviewers play in Compass also increases their evidence of impact as well as introducing them to an area which they were not previously familiar with.
\end{abstract}

Keywords: student reviewer, academic journal, co-creation, professional identity, staff-student collaboration

Acknowledgements: Thanks to Simon Walker for pushing forward the call for reviewers and for his help with the review of applications and conducting of training. Many thanks also to the PGR reviewers who applied and those who continue to work with Compass: Journal of Learning and Teaching.

\section{Introduction}

The makings of an academic journal tends to consist of all or some of the following: Editors, Editorial boards, Editorial advisory boards, and a pool of reviewers who work together to refine the direction of the journal and help to cohere each issue before publication (The Journal of Higher Education (2017), Higher Education (2017), Studies in Higher Education (2017),

The Review of Higher Education (2017) are some examples). The reviewers list for such journals are also highly likely to all be made up of colleagues working within the higher education sector, with many reviewers also sitting on the editorial board. Compass: Journal of Learning and Teaching published by the Educational Development Unit at the University of Greenwich is no different in this regard. 'Compass is a peer-reviewed cross-disciplinary research journal that welcomes articles, case studies and opinion pieces relating to innovative learning, teaching and assessment' (2017a). Students and staff are welcome to submit pieces to the journal to be considered for publication. However, the blind peer review process has since the first issue of the journal in 2009 till 2017 always been conducted by a group of reviewers who are either lecturers, former colleagues at the university, or other full time teaching staff in the higher education sector. While postgraduate researchers (PGRs) could therefore submit work for consideration in Compass, behind the scenes of the journal, the formation of each issue was previously based upon the reviews and voices of staff in $\mathrm{HE}$.

Over time, there has been a rise in the number of submissions to the journal coming from academics outside of Greenwich. This could be read as evidence that Compass is growing and making impacts further afield. The journal has therefore changed from 
being Greenwich-centric in terms of authorship and audience as it had been in 2009 when the journal made its first publication. However, was the successful growth of the journal inadvertently preventing PGRs from submitting work to Compass? Was seeing well known names publishing in the journal causing PGRs to think that the journal would not be interested in reviewing their work? By way of trying to increase levels of interaction with the journal among PGRs, it was decided that an email call would be sent out to invite them to consider submitting research to the journal and to consider the opportunity of joining Compass as a student reviewer. It was envisioned that the collaboration of staff and student reviewers would lead to the publication of a more inclusive journal.

In the introduction to 'Rethinking the values of higher education - students as change agents?' Kay et al $(2010,1)$ comment, 'the concept of the student voice can be passive and disempowered, governed and operated by the institution rather than by students themselves'. Through working closely with postgraduate researchers on Compass, their voices are listened to, respected, and engaged with. Healey et al (2014) comment: 'A simple distinction may be made between a focus of students as partners on: a) student engagement in learning, teaching and research; [and] b) student engagement in the quality enhancement of learning and teaching practice and policy' (22-23), although they also note that there is overlap between the two. This short case study which is based on a very small scale pilot trial outlines the recruitment of postgraduate researchers to work as student reviewers and take part in a form of co-creation for Compass. Three PGRs carried out reviews for the October 2017 issue of Compass. An intern reviewer was also trained at the same time as the other student reviewers but carries reviews out only for the Journal of Educational Innovation, Partnership and Change (JEIPC). Another student reviewer was also trained but has up until now only reviewed for JEIPC.

The Quality Assurance Agency for Higher Education note, 'By working together to a common agreed purpose, steps can be taken that lead to enhancements for all concerned' (QAA B5, 5).

The role which the PGRs play in reviewing situates them in a position where they are both engaging in research through their reviewing of academic work submitted to the journal, and helping to enhance the quality of teaching and learning practice through giving detailed feedback to authors. However, rather than using the term 'engaging', it may be better suited to say that the PGRs were involved in co-creation. In the context of Compass, this co-creation refers to the coming together of staff and student opinions which are fed back to authors after completion of the blind peer review process. The result is that the reviewing process becomes more inclusive of the PGR student voice as their reviews play a key role in the cohering of final pieces for each issue. In addition, working as co-creators of each issue, the role develops the professional identity and impact of evidence among the selected student reviewers. Allin $(2014,96)$ notes, 'there seem to be few articles that reflect critically on the extent to which collaborative relations with students are achieved in practice'. In this paper, the call for student reviewers and application process is outlined along with the training that was put in place.

\section{Recruitment and Training}

Co-creation projects are typically initiated by staff inviting students to join their work (Bovill et al 2016). 'This raises difficult questions of how they determine whom they will invite and which students have the capacity to contribute (Bovill et al 2016, 203)'. For this particular case, an email call was sent to an Administrator in the Postgraduate Research Office who then passed on the details to all PGRs in the university inviting them to apply to become student reviewers for Compass. [A copy of this email can be seen in Appendix A]. Discussing how to enhance inclusivity 
when it comes to opportunities for staff-student engagement, Felten et al comment $(2013,67)$ 'all students need to be informed of what [scholarship of teaching and learning] is and about the opportunities that exist for involvement in such inquiries'. By sending out the email to all PGRs across the institution, all postgraduate researchers were given notice about the opportunity, making the process more inclusive and transparent. Response to this email call was limited but additional calls for reviewers was sent and continue to be sent out to underline that the process of recruiting PGR student reviewers is a rolling call. An application process was and is still implemented as part of the recruitment stage. PGRs had to select a published text from the Compass archives and review the piece using a standard review form given to them. PGRs could choose any published text from Compass but not an opinion piece (due to the short word length of this genre, the reviewers needed to more accurately see in detail how the PGRs would review and comment on a text). [A copy of this review form can be seen in Appendix B]. This part of the process helped to ensure that any future reviews which would completed by the PGR for the journal would be to an acceptable and high standard.

Each application was peer reviewed, the feedback was then discussed and a decision was made as to whether or not their application had been successful. The turnaround time from the submission of the review to the decision making stage was carried within a few weeks at most as time needed to be allocated for training purposes. Selected PGRs were then notified by the Editor of Compass and invited to a training session where an overview of their role was given. Applicants who were not successful were also notified by email. The training session involved introducing the scope and aims of the journal more explicitly to the PGR student reviewers. Discussion then led to focusing on their previous experiences of reviewing (if any) and how they would approach a typical review. Comparisons were also drawn between the process of reviewing an article and the ways in which PGRs usually examine sources and texts for their own research (such as their PhD). It was found that similar questions and methods were used to approach both a typical textual analysis and a review of an article. Such connections, though in some ways are obvious, when discussed as part of the reviewer training helped to alleviate concerns which the PGRs may have had before the training.

Not all recruited PGRs could attend the face to face training, so another session was delivered online via Adobe Connect for those who could not make the initial session. Online resources (Compass, 2017b) were also created to help support PGRs through the process of becoming a new reviewer. It was noted that new reviewers could contact the Editor for mentoring throughout the process for additional support and guidance if needed. The latter ensured that lines of communication remained open and accessible, a vital aspect of effective co-creation (Bovill et al, 2016). The training session was also used to clarify expectations of reviewers. It was noted that PGR student reviewers would only have their name listed as a Student Reviewer on the online and print issue(s) for which they have carried out reviews for. Moreover, for every Compass submission, only one PGR student reviewer would be assigned to each peer reviewed submission, so that there would be a balance of views between standard and student reviewer. This helped to emphasise that the recruitment of student reviewers was not to extend the size of the pool of reviewers but to increase the participation of PGRs with the journal. It would also reassure the PGRs that their reviews alone would not be the deciding factor for whether a submission was accepted or rejected from the journal, which if had happened, may have caused some levels of concern as the PGRs had very limited experience reviewing academic work for a journal context before. 


\section{Follow up and reflections}

A follow up meeting with the PGRs was organised to touch base with the reviewers and discuss their experiences and reflections on the process. Due to clashes in timetables, a face to face meeting with all the reviewers was difficult to arrange and so a couple of PGR student reviewers met with the Editor for an online meeting via Adobe Connect session instead. Student reviewers noted that they were content with the number of reviews they were being assigned for Compass and were pleased that they were participating in the peer review process. One concern they had was how authors and the Editor were receiving their reviews. The student reviewers were slightly worried about whether their reviewers were clear and detailed enough. This was an understandable concern among the student reviewers as they had not reviewed for the journal before and are unable to see the completed reviews of others on the Compass web system. This led to the student reviewers not being able to compare their review(s) with those of others, which if they were able to, would have helped to alleviate some of the anxiety they experienced.

The issue of hierarchy and power between staff and students can be a concern during the process of collaboration and has been discussed by Allin (2014). In the context of this case study for Compass, the concern over the theme of power relations was also raised in discussion. The PGRs sought reassurance that their reviews were of a suitable standard and wanted to know whether they were in line with the thinking of the standard reviewers. Such questions have not been raised by anyone from the standard pool of reviewers. This subtle underconfidence among the PGRs suggested that they perceived the reviews of the standard reviewers as being in some way 'better' through their experience of reviewing, even though the PGR student reviewers had already completed a successful review as part of the application process, and had completed the necessary training. The discussion points to how increased levels of collaboration and co-creation between staff and students can help to develop the confidence of students in their abilities and skill-set. As PGRs can sometimes perceive themselves as straddling the line between staff and student (Compton and Tran, 2017), projects which explicitly value the views and collaboration of PGRs can also help to enhance their feelings of belonging.

The peer review process for Compass arguably helps to make the perceived hierarchy between staff and PGRs more balanced as both standard and student reviewers complete the same task anonymously. If both a standard and student reviewer is assigned to the same article, neither can see the other person's review and so there is no judgement or hierarchy of any kind between the two reviewers. As it is currently, the Compass blind review process only allows the Editor and Journal Administrator to view the allocation of submissions to reviewers. The restriction of even anonymised reviews from being visible on the system to other reviewers helps to prevent one or more reviews from influencing another. The difference in review opinions and comments can greatly help to share with authors a range of detailed and developmental feedback. However, going forward it may be useful to have snippets of reviews to be used as part of a discussion activity for future student reviewer training sessions so as to help alleviate the concerns of the PGRs as expressed during the catch up meeting.

During the follow up meeting online, the Editor reassured the student reviewers that their reviews had been timely, clear, and incredibly helpful to the authors receiving them. Authors receiving the reviews were not told if a review was completed by a standard or student reviewer. This anonymity means that the student and standard reviewers are not divided into separate categories when the author receives their feedback. All sets of reviews therefore hold the same value. Bovill et al 'contend that academic staff should not only consult students but also explore ways for students to 
become full participants in the design of teaching approaches, courses and curricula' $(2011,133)$. Although Bovill et al are not in this statement referring to the context of co-creation for a journal, this 'moving away from traditional hierarchical models of expertise' can still be said to come into play here (ibid). The result is that all the reviews (no matter who wrote them) are treated with the same respect when they are sent to authors. The latter also highlights the high standard of the student reviews as they are consistent in quality with those completed by colleagues from the pool of standard reviewers who have had much more experience with reviewing.

Through being a student reviewer for Compass, PGRs are not only exposed to a new developmental experience, but are able to use the opportunity to enhance their transferable skills which can help them to grow as both researchers and professionals. While their focus is primarily their doctoral research, any additional teaching roles and reviewing responsibilities which the PGRs may take on during this time help them to carve out an identity in the Higher Education workplace where they are seen not only as postgraduate researchers but as engaged and involved colleagues in the institution. As a result, student reviewers were encouraged to list their affiliation with the journal on their curriculum vitaes. Such a reviewing role also enhances their analytical and written communication skills, which are highly desired skills for any work based role. By gaining these 'increased employability skills' (Jarvis et al, 2013, 223), the PGRs are active in shaping their professional identity. The benefits of staff and student partnership in this context results in adding value to the quality and range of feedback authors receive, the production of a more inclusive journal, while helping PGRs to also evidence their impact. As student reviewers (and PGRs in general) can also submit work to the journal, if their submission is published, this would act as further evidence of impact.

\section{Conclusion}

The pilot of recruiting, training, and working with PGR reviewers has been successful (albeit with a limited sample size). Going forward, training will need to be enhanced based on comments from follow up meetings with student reviewers. As the current student reviewers expressed gratitude at the arrangement of the follow up meeting as they felt respected, involved, and supported through the reviewing experience, it is important to continue to keep such lines of communication open. As more PGR reviewers join the journal, future meetings with new and experienced student reviewers will be arranged so that those who have gone through the process can share their experiences and advice with new student reviewers. The role of the PGR student reviewer will now also be logged on to their Higher Education Achievement Record (HEAR at UoG, 2018). The latter acts to formalise their involvement with the journal, emphasising their voluntary critical contribution. By emphasising the evidence of impact which can be made and the formalising of their contributions on their HEAR records, it is hoped that greater numbers of PGRs will be interested in participating as student reviewers.

It is important to disseminate the value which can come through staff and student collaboration projects. Recently, the recruitment of PGRs as student reviewers for Compass was presented as a poster at the Graduate Teaching Assistant Developers Conference: Pathways of Development for Early Career Educators (2017) in Stirling this year, which received positive feedback from peers. Future plans include recruiting more student reviewers to continue to increase the levels of co-creation in the journal. Working with PGRs on the reviewing of submissions for Compass during this pilot trial has proven to be a fruitful and developmental experience for all involved - the PGRs, the Editor, and the authors. It is not only course content and the 
structure of curricula which staff and students can work together on. This pilot trial has shown that other areas of academia can also be used as spaces for co-creation. 


\section{References}

Allin, L. (2014). 'Collaboration between staff and students in the Scholarship of Teaching and Learning: The potential and the problems', Teaching and Learning Inquiry, 2(1), 95-102.

Bovill, Catherine, Alison Cook-Sather \& Peter Felten (2011). 'Students as co-creators of teaching approaches, course design, and curricula: implications for academic developers', International Journal for Academic Development, 16:2, 133145.

Bovill, C., A. Cook-Sather, P. Felten, L. Millard and N. Moore-Cherry (2016). 'Addressing potential challenges in co-creating learning and teaching: overcoming resistance, navigating institutional norms and ensuring inclusivity in student- staff partnerships', High Educ, 71:195-208.

Compass (2017a). Available at: https://journals.gre.ac.uk/index.php/compass (Accessed: 22 August 2017). 22/8/17].

Compass (2017b) 'Guidance for new reviewers.' Available at:https://www.smore.com/p342p (Accessed: 22 August 2017).

Compton, M. and D. Tran (2017) Liminal space or in limbo? Post Graduate Researchers and their personal pie charts of identity, Compass (10:3). Availble at: https://journals.gre.ac.uk/index.php/compass/article/view/620) (Accessed: 15 January 2018].

Felten, P., Bagg, J., Bumbry, M., Hill, J., Hornsby, K., Pratt, M., \& Weller, S. (2013). A call for expanding student engagement in SoTL. Teaching and Learning Inquiry, 1(2), 63-74.

GTA Developers Conference: Pathways of Development for Early Career Educators, Monday 19 June from 12.00 to 18.30, and Tuesday 20 June 2016 from 9.30 to 16.00 , University of Stirling.

Healey, Mick, Abbi Flint and Kathy Harrington (July 2014). 'Engagement through partnership:

students as partners in learning and teaching in higher education', Higher Education Academy Available at:

https://www.heacademy.ac.uk/system/files/resources/engagement through partners hip.pdf (Accessed: 23 August 2017].

HEAR at University of Greenwich (2018). Higher Education Achievement Report. Available At: http://www2.gre.ac.uk/current-students/your-official-documents/hear (Accessed: 15 January 2018].

Higher Education: The International Journal of Higher Education Research (2017). Available at:

http://www.springer.com/education+\%26+language/higher+education/journal/10734? detailsPage=editorialBoard (Accessed: 22 August 2017). 
Jarvis, Joy, Claire Dickerson, Lewis Stockwell (2013). 'Staff-student partnership in practice in higher education: the impact on learning and teaching', 6th International Conference on University Learning and Teaching (InCULT 2012), Procedia - Social and Behavioral Sciences 90, $220-225$.

Kay, Janice, Elisabeth Dunne and James Hutchinson (2010). The Quality Assurance Agency for Higher Education, Gloucester. Available at:

http://dera.ioe.ac.uk/1193/1/StudentsChangeAgents.pdf (Accessed: 22 August 2017].

QAA, The UK Quality Code for Higher Education, Part B: Assuring and Enhancing Academic

Quality, Chapter B5: Student Engagement. Available at:

file:///C:/Users/dt4110x/Downloads/Chapter\%20B5-

\%20Student\%20Engagement\%20(2).pdf (Accessed: 15 January 2018].

Studies in Higher Education (2017) Published on behalf of the Society for Research into Higher Education. Available at:

http://www.tandfonline.com/action/journallnformation?show=editorialBoard\&journalC ode=cshe20 (Accessed: 22 August 2017].

The Journal of Higher Education (2017). Available at:

http://www.tandfonline.com/action/journallnformation?show=editorialBoard\&journalC ode=uhej20 (Accessed: 28 August 2017].

The Review of Higher Education (2017). Available at:

https://www.press.jhu.edu/journals/review-higher-education/editorial-board (Accessed: 22 August 2017].

\section{Appendix A}

[Below is a copy of the email sent out to all PGRs at the University of Greenwich in February 2017. Additional emails were sent after this time to continue the call for PGR reviewers].

Subject heading: Opportunity to join the Compass journal as a PGR reviewer

Dear Colleagues,

Hope this finds you well.

You may already be familiar with the university's journal - Compass: Journal of Learning and Teaching. 
I am Editor of the journal and would very much like to incorporate greater levels of PGR engagement with the journal. One of the ways in which I can try to achieve this is through encouraging you to submit articles/reviews/case studies/reviews etc to the journal. More information can be found via the link below (including how to subscribe to the journal).

\section{https://journals.gre.ac.uk/index.php/compass/issue/view/48}

However, another way in which I can build upon PGR engagement is by inviting you to consider the opportunity of joining the journal as a PGR reviewer.

If you would be interested in becoming a PGR reviewer for the journal, we ask that you review a published article in Compass (the choice of which article to review is up to you, but please make this clear in your written review, e.g. By including a link to the submission). Your review will then be assessed by the Compass team who will get back to you with feedback and a decision. I have attached a copy of the review form which we ask you to use.

If you do become a PGR reviewer, your name would only be listed as a reviewer in the print and online versions of the particular issue which you contribute to. Also, for every submission, only one PGR reviewer would be assigned to each peer reviewed submission, so that there is a balance of views.

Any further questions, please do get in touch.

All best wishes,

\section{Appendix B}

[Below is the article review form which was sent to PGRs who were interested in applying to be a PGR reviewer for Compass].

\section{Compass article review form}

\section{Please rate each of the following components out of 5}

\section{To what extent is the article...}

high)

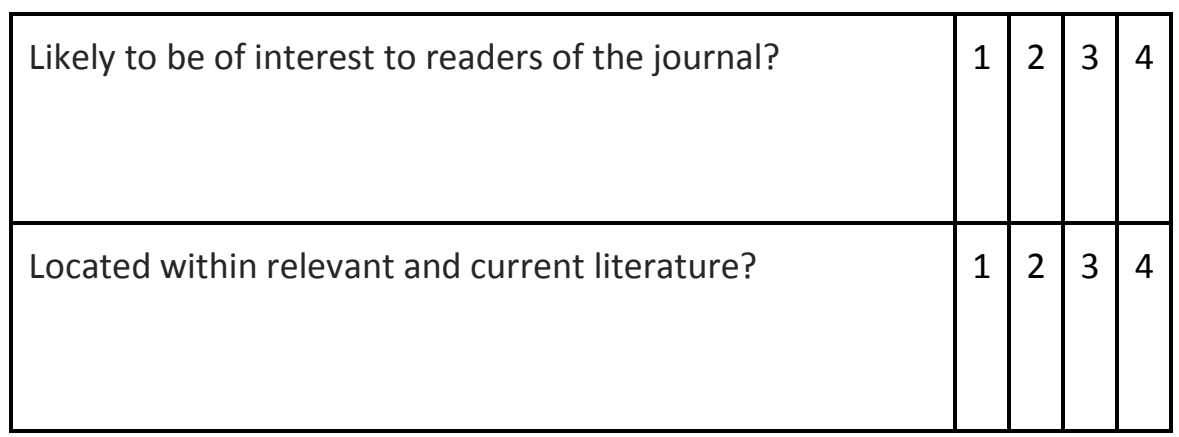




\begin{tabular}{|c|c|c|c|c|}
\hline Making an original contribution? & 1 & 2 & 3 & 4 \\
\hline Presented in a style appropriate for an academic journal? & 1 & 2 & 3 & 4 \\
\hline Accurate and up to date? & 1 & 2 & 3 & 4 \\
\hline Demonstrating a good standard of argument and analysis? & 1 & 2 & 3 & 4 \\
\hline Appropriately referenced? & 1 & 2 & 3 & 4 \\
\hline Of appropriate length for type? & 1 & 2 & 3 & 4 \\
\hline
\end{tabular}

Comments for the author(s)

Strengths of the article

Comments for the author(s)

Suggestions for improvement

Any other comments, for the editors only 